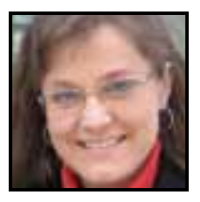

\title{
Holistic Education: A Pioneer Narrative
}

\author{
Jane P. Preston, University of Prince Edward Island
}

\begin{abstract}
This article is based on the personal narrative of a Canadian pioneer woman who grew up during the 1920s and 1930s. The story epitomizes a holistic approach to learning, which embodies facets of family, community, and the land. Conceptualized through narrative inquiry, the purpose of the article is to capture an innovative meaning for holistic education. I employ Deweyan philosophy as an analytical lens for her story and provide pedagogical relevance to the narrative.
\end{abstract}

\section{Introduction}

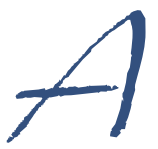

story that is founded upon historical events and has present-day significance holds great potential to resonate with a variety of readers. This statement represents the hope of this article. Recounted in 2012, the personal narrative depicted herein is the voice of an 86-year-old, Germanic, first-generation Canadian woman. The description of her youth represents her intellectual, emotional, spiritual, social, and historical knowledge and embodies the social conditions that were experienced by many pioneer people living on the Saskatchewan Prairies during the 1920s and 1930s. Conceptualized through the woman's story, the purpose of this article is to capture an innovative meaning for holistic education. An offshoot of the woman's holistic learning is that it influenced the present-day lifestyle and pedagogical views of her daughter.

Stated upfront, the woman in this story is my mother, and the aforementioned daughter is me. Rephrasing the purpose under these boundaries, this article highlights my mother's dominant life lessons learned while negotiating an existence 
within the natural environment. The article includes an explanation of how my mother's holistic education is intergenerational, as some of it exists within me, the youngest of her seven children. In addition to the personalized information threaded throughout the article, I explain the genesis of the concept of holism and provide modern definitions of holistic education. I explain the methodological approach used in collecting the narrative data and discuss the past, present, and future essence of narrative inquiry. I supplement aspects of my mother's story by employing features of Deweyan philosophy as an analytical lens, and I provide pedagogical relevance to the narrative.

The information contained herein is significant for a number of reasons. First, my mother's story is first-hand documentation of the positive and challenging experiences of a Canadian pioneer family living in the Prairie Provinces; such verifications are becoming increasingly isolated during modern times. Another reason why this article is noteworthy is that a large portion of this writing depicts holistic education via a non-academic worldview. Holistic education is about life experiences, which are not solely bound by kindergarten to grade 12 schooling or postsecondary education. Knowledge and education should not be exclusively defined or confined within the walls of schools or educational institutions. Although this point has limited voice within academic literature, it is a dominant thread woven throughout my mother's story.

\section{Origins and Modern Description of Holistic Learning}

The concept of holistic education stems from the overarching philosophy of holism. In his epic book entitled, Holism in Evolution, Smuts (1926/1987) first coined the term holism, where he uses it to describe the natural mechanisms of the universe. More specifically, he states ${ }^{1}$ that holism is:

The ultimate synthetic, ordering, organising, regulative activity in the universe which accounts for all the structural groupings and syntheses in it, from the atom and the physico-chemical structures, through the cell and organisms ... The all-pervading and ever-increasing character of synthetic unity or wholeness in these structures leads to the concept of Holism. (p. 317)

Smuts continues his explanation of holism by expressing that the whole is greater than the sum of its parts. This point implies that the individual pieces of any 
all-encompassing system, organization, or entity neither can exist nor be fully understood unless each piece is related to the functioning of the entire structure. The living environment constitutes a web of relations (McDonald, 2004). As Tolle (2005) points out, "All things in existence, from microbes to human beings to galaxies, are not really separate things or entities, but form part of a web of interconnected multidimensional processes" (pp. 275-276). This concept of omnipotent wholeness is exemplified aesthetically through the sense of awe that one might feel when viewing a picture of planet Earth taken from outer space or when witnessing the overhead vastness of an endless starry night-scenarios that emit feelings of pure harmony.

Modern literature contains many hybrid phrases developed from Smuts' notion of holism. In particular, holistic learning and holistic education are popular expressions often used by academics and other educational leaders in a variety of settings. Within schools and formal educational environments, a general aspect of holistic learning is the provision of education where demarked, specialized subject content (e.g., English, math, art, biology, etc.) becomes blurred. Instead, subject-specific knowledge is transformed into experiences that are interrelated, interconnected, intersected, integrated, incorporated, interdisciplinary, and interdependent. As Miller (2006) explains, "Holistic education cultivates a curriculum of connections" (p. 101). An underlying principle of holistic learning is that education is effectively acquired when individual parts of knowledge are synergistically connected to each other.

Holistic education also promotes the importance of teaching the whole child (Miller, 1997, 2000, 2005, 2006, 2010), which includes intellectual, emotional, physical, social, aesthetic, and spiritual aspects of the individual and his/her learning process. Orr (2005) defines holistic education as "[striving] to teach the whole person as a human soul which includes mind, body, emotions, and spirit" (p. 87). Maria Montessori refers to fostering a type of cosmic education where children gain a sense of self-purpose through hands-on experiences nurtured within a perfectly synchronized universe. In referring to cosmic education and the child, Mario Montessori (Maria Montessori's son) (1992), believes cosmic education develops "their [children's] minds, their visions, and their creative power, whatever the level or range of their personal contributions may be" (p. 101). Aboriginal epistemology also aligns with the notion of educating the whole child. From an Aboriginal stance, education is about strengthening one's mind, body, emotions, and spirit and, in turn, balancing one's physical and metaphysical features to experience a fulfilled life. Many other authors refer to the importance of implementing pedagogy that promotes teaching the whole child, rather than prioritizing knowledge-based learning. For example, through personal teaching examples, Kessler (2004) and Preston (2012) describe how 
to foster learner spirituality within the classroom. Palmer (1998) and Moore (2004) speak about promoting a type of teaching that inspires the soul of the child. In all these references, educating the whole child is much more than just attending to a set academic agenda; it is about promoting the richness of a balanced, physical-spiritual lifestyle that is open to multiple ways of learning, knowing, and experiencing.

In relation to these popular descriptions of holistic education, within this article, my reference to holistic education is somewhat unique. In a simplistic and general sense, I define holistic education as dominant lessons learned from experiencing life. Every person is undergoing a distinct lifelong learning journey; in turn, everyone possesses a type of exclusive certification in holistic education. Because every individual begins life at a unique starting point and, throughout life, is accompanied by varying degrees of support and challenges, it is impossible for everyone to acquire one dominant learning experience. Furthermore, there are many and varied options in life; each chosen decision abounds with knowledge, wisdom, challenges, and pain. These personal experiences generate contextualized dominant life lessons. Through the narrative data, I document one woman's starting point and present a unique aspect of her holistic learning journey.

Aligned with my definition of holistic education are core features of Deweyan philosophy. Dewey asserts that education is the full experience of living, and he criticizes the supposition that learning only happens in schools, colleges, and universities (Hansen, 2006). In Dewey's book, Democracy and Education (1916), he argues that any person who understands how to learn and is open to interactive learning experiences is well posed to becoming an active democratic citizen. With that stated, Dewey does not confine the concept of democracy to an electoral process and its political structures. Rather, he believes a democratic citizen is someone who prioritizes the ability to resolve problems, anticipate and plan for possibilities, remain modest in one's claim to truth, and to act on what is good for the individual, the community, and the society at large. "According to Dewey, education, democratic life, and human flourishing are all one" (Hansen, 2006, p. viii). These philosophical concepts are interspersed throughout my mother's pioneer story.

\section{Narrative Inquiry and Methods of Data Collection}

Elliott (2005) states, "Stories rely on the presumption that time has a [linear] direction, moving from past to present to future" (p. 7). Dewey (1938) emphasizes 
the continuity of an experience by saying, "Every experience lives on in further experiences" (p. 27). Likewise, Clandinin and Connelly (2000) state, "Experiences grow out of experiences, and experiences lead to further experiences" (p. 2). The views of these authors highlight that describing an experience means referencing the historical past, understanding it in real time (the present), and enabling it to evolve in the future. Through the application of a narrative research design, I document the experiences of a pioneer woman and attend to the past, present, and future aspects of her story. More precisely, in what follows, I describe my mother's youth, therein describing the origins of her holistic knowledge. I fast-forward to the present and discuss how I inherited aspects of her holistic education. As well, I ponder about the ways in which my mother's story might influence others in the future. In sum, through the incorporation of narrative inquiry, I attempted to gain a fuller understanding of the continuity of my mother's lived experience (Clandinin \& Connelly, 2000; Clandinin \& Rosiek, 2007).

\section{Comfortably and Credibly Documenting Mother's Story}

As the starting point for the collection of my mother's history, I asked her if we could have a semi-formal conversation and explained what this process would involve. I would supply her with 8 to 10 open-ended questions, which she could review before our actual discussion. We would then set up a time for a visit, and I would formally ask her these guiding questions. I told her I intended to tape the entire conversation, create transcripts from the dialogue, and provide her with an opportunity to check the discussion transcripts. Even though, in other research endeavors, I had utilized a similar format to document personal information, my description of the data collection process deterred my mother's interest. She explained that the tape recorder intimidated her, and she feared she would not be able to answer the questions properly. She voiced concern about the potential negative effects of using technology to infinitely store her life; she was concerned that the recorder would amplify the grammatical mistakes she might make when talking. In response to her apprehension, I asked if she would be more comfortable with simply writing out answers to questions. She liked this idea and perceived that a written response would both alleviate conversational jitters and provide her with the time she needed to contemplate answers before responding.

Following this initial discussion, I provided her with 10 questions, which I believed to be conducive to narrative answers. Questions/statements included: "Tell me about your childhood, your family, and how you grew up." "Describe a typical day when you were a young girl living on the farm." "Tell me about a time when you or 
your siblings were sick and how your family dealt with this sickness." "What kind of food did you eat and how did you prepare it?" Under this guidance, she completed about 15 pages of hand-written answers. ${ }^{2}$ In an effort to aid the readability and flow of the narrative, I typed out her written answers, while attending to minor grammatical and writing issues. During this review of her answers, I found that, in some areas, I wanted more detail; in such a fashion, her story generated follow-up questions, which I mailed to her. After a couple of weeks, she provided me with an additional five hand-written pages. I typed out these new responses (again attending to minor grammatical and writing issues). I added the new information to her former work, and provided her with a copy of all the answers she had generated. I asked that she check the compilation of answers to ensure that the meaning she initially intended to convey was accurately presented within the typed transcript of answers (Inman, Howard, \& Hill, 2012; Lincoln \& Guba, 1985; Stake, 2010). In writing the final draft of this article, I once again transformed aspects of her written answers (e.g., inserting adjectives, connecting simple sentences, etc.) to create her biographical narrative. When finished, my mother and I sat together and read her entire story to ensure that the narrative was an authentic representation of her youth.

\section{My Mother's Story}

I am a mother of seven children, a grandmother of 12 children, and greatgrandmother of 11 children. All my life, I have been a homemaker and worker of the land, but, in particular, on these pages, I reminisce about my early life experiences, giving my memories of when I was a young girl growing up with my mom, dad, and 12 siblings. My youngest daughter asked me to describe my youth and the knowledge I gained from these experiences. She believes my recollection of living through the Dirty 30 s contains specialized information about pioneers and the way in which they depended on the land for food, entertainment, and all aspects of existence. I never thought my story was of any importance or interest to anyone, as my story is typical of people my age who lived from the land; however, my husband and many of my family members and friends have now passed on, and I realize that perhaps my story is becoming an informational artifact about life in the early 1900s. Perhaps my daughter can find a use for my story and in that process support her own growth and, in some fashion, someone else's growth. That would be nice. 


\section{Establishing the Basics From the Land}

I was born in the fall of 1925 , the third of 12 children. As a young child, I remember my father taking up a homestead in northern Saskatchewan, where he bought 160 acres of bush-land from the government. At that time, he paid $\$ 10$ under the agreement that for the next three years, he would clear and plant 10 acres of newly broken land each year. To meet this grave, labour-intensive commitment, all the family members were required to cut down trees with axes, pull out roots and stumps, clear away heavy rocks, and then plough and seed the black, rich, virgin land.

Obviously, we needed a place to live during this process, so we built our house with wood reclaimed from the trees during the clearing and cultivation of the land. To build our house, which contained a kitchen and three bedrooms, we chose the prize logs and stripped off the bark and branches. To construct each of the four walls, logs were piled atop of each other, and the cracks between the logs were filled with plaster prepared from mud, straw, and water. In each corner, the logs were fastened with wooden pegs, which we constructed from whittling wood into peg-like shapes.

During the construction of our house, we did not build a chimney; rather a stovepipe ran from our kitchen stove upward into the roof. Our trusty and beautiful stove was a seminal part of our existence. Not only did we use the stove for preparing meals, canning fruits, canning vegetables, and preserving meats, this wood-burning furnace was our only heat supply; other than snuggling close to family members while sleeping, our stove was the one thing that prevented us from freezing during the bitter cold winter months.

It seems that everything we took from the land was put to great use; little went to waste. This point held true for the wood ash we collected from our stove. In the spring, we sprinkled this ash into the garden rows before sowing the seeds; the ash was a natural deterrent for seed-eating worms. In the late summer, the valuable wood ash was sprinkled on the potato plants and cabbage plants, because the ash was a natural pesticide for potato bugs and white butterflies. We also used wood ash to soften our water. About once a week in the evenings, we filled a 45-gallon barrel of water drawn from the hand-dug well and stirred two or three gallons of ash into the water. By morning, the ash had settled to the bottom of the barrel and transformed the hard water into soft water, which was needed for washing clothes.

On the topic of washing clothes, our precious water was drawn from a 15-20 foot well that we dug by hand. We heated the water on our cook stove and poured 
the boiling water into a hand-turned, wringer-style washing machine. Towels, dishcloths, and other heavy soiled clothes had to be hand-scrubbed on a washboard before going into washing machine. For us, bleach did not exist. Rather to ensure brightness, we boiled our white clothes, underwear, and flour bags on the stove. We hung the germ-free clothes and flour bag material on the wash line, and they were bleached with sunlight. Soap was made by boiling lard, tallow, and lye; the lard and tallow were supplied from the butchering remnants of hogs and cattle, and the lye was purchased in small cans from the store. These ingredients were cooked together, cooled, and cut into soap bars.

\section{The Environment Provided}

All around us, the environment provided us with ample food and supplies. The wild blueberries, strawberries, raspberries, cranberries, pin-cherries, chokecherries, and swamp blueberries made delicious pies and tasty jams. In addition to being a bountiful food source, picking berries was fun, because it usually involved the five oldest children walking and crawling through the bushes, the girls singing loudly as we quickly filled the gallon pails tied around our waists.

The large majority of the meat we ate was wild-deer, moose, rabbit, and prairie chickens were shot in the fall. As a child, we cleaned the rabbits, after dad killed them. I can still remember the smell of those rabbits, which, to me, was not a very good smell at all! Often my family and the neighbors got together to butcher cattle and hogs; they cut up the meat and divided it among them. Sometimes, we butchered our own meat, and, in those times, we preserved large quantities of raw meat by soaking it in a strong brine solution for a week or so. (The brine had to be salty enough so a raw egg would float on top of it.) Other meat was preserved by curing it in our smokehouse. We caught and canned a lot of fish, too. We cleaned the fish, packed it into 2-quart glass jars, and placed the 14 jars into a big boiler. We set the boiler on the wood stove and cooked the fish-filled jars for three hours. After the jars cooled, this treasured food was stored in our dirt cellar.

Chickens and cows were important to us, too. We raised our own chickens by setting the clucks. To help them set, we made them a soft straw nest in an isolated area where no other chickens or animals would bother them. We provided them with grain and water and let the clucks sit on their eggs for three weeks until the chicks hatched. As for the other hens, we ate their nutritious eggs and, throughout the year, butchered chickens when needed. Our cows provided us with a plentiful supply of milk and rich cream. We loved to drink frothy warm milk straight from the cow. We 
were thankful for the cream (retrieved from a hand-turned cream separator), and we churned much of the cream into butter, which we used for many things including making a rich array of scrumptious desserts.

We also canned many vegetables transforming them into mustard beans, yellow bean pickles, beet pickles, sweet and sour pickles, and dill pickles. As children, we ate a lot of homemade vegetable soup made from the peas, corn, and carrots grown in the garden. We ate rhubarb straight from the garden; it was good, especially after coming home from school when we were very hungry. During the winter months, we also consumed an abundance of carrots, turnips, and beets, all of which were root-plants that kept well in the cellar.

In particular, sauerkraut, a type of preserved cabbage, was very important to us. Throughout the year, we always had a big wooden barrel of sauerkraut sitting in the cellar. To make this delicious food, first, with a special cutter, we shredded a couple of heads of cabbage and added a few handfuls of salt. Then we pounded the salted, shredded cabbage with a big piece of wood (like a baseball bat); juice emerged from the mixture. Layer after layer, we repeated the process until 100 or so cabbage heads were cut, salted, and pounded, forming a mixture of salty juice and mushy cabbage. We covered the mixture and let it ferment in a 30-gallon barrel for six weeks, after which time it was ready to eat. During the winter months and as we needed it, we took the preserved sauerkraut out of the barrel. We cooked it on the stove, sometimes adding pork, and enjoyed it with homegrown mashed potatoes.

The environment and animals not only supplied us with food but with warm blankets and clothes. We sheered our sheep, and grandma washed the raw wool several times, ridding it of its natural oil. This wool made the nicest, warmest quilts that were widely used by everyone in our family. Grandma also had a spinning wheel, and she spun the sheep wool into yarn, which served many purposes including knitted socks, mitts of all sizes, and supplies for darning clothes. Our pillows were made from chicken feathers, but only the breast feathers would do, because these feathers were nearest to the bird's body; thus, they were the softest. Every fall we made new straw mattresses for our beds, because after a year of sleeping on a straw mattress, the mattress would become thin and worn.

\section{Health and Home Remedies}

Although I cannot prove it, it is my recollection that during my younger years, children and adults did not seem to get sick to the extent that they do today. 
Having stated such, occasionally, we did get sick, but I do not remember anyone in our family ever going to the doctor for an illness. Perhaps one of the reasons we did not visit the doctor was because he was too far away. Thirty miles was a long way for horse-and-buggy transportation. Luckily, we had a selection of home remedies to treat cuts, sores, and other ailments. For example, we applied axle grease to infections and covered the injured area with a cloth. The grease drew out the puss. From nearby swampy areas, we collected a special mud. We fashioned a poultice from this mud and used it to treat infections and cuts. We dabbed clove spice onto teeth and gums when someone had a toothache. One spring, my siblings and I had a bad bout of ringworm, which my mom doused with a type of liquid that caused a strong burning sensation. For heartburn, we drank a water-and-soda mixture; it would make you burp and feel better. During the time a woman was about to deliver a baby, the other family members of that house were sent to a neighbor's place. Specialized women within the community came to help the woman who was about to give birth. Then other women in the community would prepare and deliver food to the household of the new baby.

\section{Some Time for Fun}

Although we always had a lot of work to do, my siblings and I sometimes played games. We played a game we called Scrub, which was a ballgame for four or five people. One person was the pitcher, one the catcher, one the batter, and one or two people were fielders. The batter hit the ball, ran to an end line about 50 feet away, and ran back to the batter's original spot. If the batter ran to the line and back to his/her original spot before being touched by someone else, the batter would gain a point and could bat again. We loved to skip, too. We picked up the twine strings lying in the straw pile. We knotted one side of the strings together, braided them into a rope, and used the rope for skipping either by ourselves or as a group. The girls also played hopscotch by taking a stick and drawing a 10-squared diagram in the dirt. As a kid, I remember my delight in finding some thin cardboard and making a deck of cards from it. Oh, the fun we had with those cards! Also, I recall making a checkerboard from that cardboard and using buttons for the checkers. My brothers used to make dog harnesses braided from twine strings. They hooked up the dogs to a sleigh, which, of course, was also homemade. My brothers were also interested in music. One brother would take dad's accordion and try to play it, and eventually he became quite good at playing the instrument. Then my Dad got a banjo, and my other brother would take that and play it. It was great fun listening, singing, and dancing to the music they made by ear. 
Entertainment also involved spending time with the people in our surrounding area. Sundays after Church, Dad sometimes took us to the neighbors, who lived about a mile and a half from our place. They had a gramophone, which is like a record player wound by hand. We would listen to that wonderful invention for hours, and then we would walk home again. The school picnics were also a fun occasion. We called these school picnics Field Days, and families from different schools throughout the larger area would come together for the day. There were ball games, races for kids, high jump, etc. The lucky children would win first, second, or third prize tickets valued at $5 \xi, 10 \xi$, or $15 \xi$, which they spent on ice cream, chocolate bars, and hard candy that were sold at a special booth set up for the event.

\section{Ending Remarks}

From these experiences, by the age of 11 , I could and was expected to make bread, churn butter, milk cows, wash dishes, wash the cream separator, scrub floors, pick weeds in the garden, and cook, bake, and help prepare meals for my family. Also, during those busy times, my siblings and I walked to school located four miles away from our home. I only went to school until grade 7, and I missed a lot of school because of the work we were expected to do at home. Nonetheless, I learned to read, write, and do math even though we had few supplies at school and only the odd piece of paper and a couple of stumpy crayons at home. Although we had little money, we did not consider ourselves poor. Living in such generous natural surroundings, equipped with an ample supply of food and shelter, and blessed with the presence of family and friends, we were rich by the standards of our day.

\section{Discussion: Mother Meets Dewey}

In the initial version of this paper, I did not include a theoretical component, because adding such an academic dimension to the narrative, to me at first, seemed inconsistent with respecting my mother's story and the relevancy it held for her. My mother knows nothing about John Dewey and is confused as to why I would use another man's ideas to analyze her life. For my mother, holistic education is about practicality; thus, the philosophical aspects of this article are strange and foreign for her. In contrast, within colleges and universities, much value and credibility are given to writing that successfully utilizes theory to more fully describe a phenomenon. Accentuating this point, academic, Pierre Bourdieu (1988), reminds researchers, "Research without theory is blind" (pp. 774-775). As a middle ground 
toward respecting both my mother's and academia's value systems, in what follows, I discuss the key features of my mother's holistic ways of knowing, while incorporating abridged explanations of Deweyan ideology.

\section{Holistic Education: Practical, Concrete, and Continual}

My mother's holistic education was not founded on formal academic schooling. Instead, whether it was survival skills (e.g., how to build a house, set a cluck, make sauerkraut, etc.) or entertainment (e.g., singing while berry picking, making a deck of cards, enjoying music with neighbors, etc.), my mother's holistic education was based on the connections with family and with social and natural surroundings. In such a manner, for her, holistic education was defined as constant, cooperative negotiations between herself, other people, and the natural environment. Dewey and his daughter, Evelyn Dewey, recognized the value of such holistic education when they explained that formal schooling is a minor aspect of a holistically educated person:

What is learned in school is at best only a small part of education, a relatively superficial part; and yet what is learned in school makes artificial distinctions in society and marks persons off from one another. Consequently, we exaggerate school learning compared with what is gained in the ordinary course of living. (Dewey \& Dewey, 1915, pp. 1-2)

In the world of formal education, my mother has a grade 7 education, but, in her home community, she is a smart, wise, well-educated person.

For many reasons, educators often prioritize intellectual book knowledge over practical forms of learning. Influenced by the specific lifestyles of students, educators must strive to structure courses and arouse learner interest so that the content teacher present is practical for students. Dewey speaks to the importance of teachers designing student-focused lessons. He believes teachers need to align the learning experiences that students encounter in the classroom with the knowledge students need outside of school (Simpson, Jackson, \& Aycock, 2005). I believe my mother would agree with Dewey.

Not only did my mother's holistic education evolve from practical knowledge (e.g., fall is the time to hunt, the softest feathers are nearest to the bird's body, etc.), her education was her actual participation in concrete activities, as exemplified through growing a garden, milking a cow, and making straw-filled mattresses. Dewey states that concrete experience is authentic education; however, he also stipulates 
that mainstream educational practices often promote student learning via artificial circumstances (Kliebard, 2006). Dewey claims that high levels of learning are enticed through the process of student engagement and that conventional subject matter (e.g., mathematics, history, literature, and science) is organized knowledge that has its genesis in concrete, ordinary personal experiences (Kliebard, 2006). Aligning this point with the realities of modern classrooms, educators need to promote handson learning, service-learning, and journey-person/trades opportunities in the class. Through these types of concrete learning experiences, there is great potential for students to work collaboratively, to offer services to their community, and to engage in active forms of citizenship (Thomson, 2006).

A third point stemming from my mother's holistic educational experience is that the knowledge she gained at a very young age is long term, and she uses it to help others. Likewise, Dewey refers to the importance of continuity and the interaction of an experience when saying, "We use our past experiences to construct new and better ones in the future. The very fact of experience thus includes the process by which it directs itself in its own better [and the better of others]" (Dewey, 1920, p. 95). Because of her holistic education, my mother is wise; she is the one I phone when I want to make strawberry jam, sauerkraut and dumplings, or dill pickles, for example. I seek her trusted advice when my son is sick or suffers from a high fever. Teachers invite her into their classrooms to speak to young children explaining how people survived without electricity or modern conveniences. Indeed, she uses her wisdom for the better of others.

\section{Passing on the Knowledge}

As articulated throughout my mother's narrative, she was grateful for the abundant resources that surrounded her, and, to this day, my mother lives frugally. She reuses every plastic container and bag she acquires, patches the family's clothes, sews quilts for family and friends, cooks the vast majority of her meals, and plays cards as a form of entertainment. She lives a humble lifestyle, personally consuming little but giving much to her family and friends. In direct and indirect ways, the continuity of mother's holistic education involves passing on these social and environmentally friendly values to her children. For example, as a young child and teenager alongside my mother and other family members, I milked cows, tended the garden, picked wild berries, canned fruits and vegetables, and butchered chickens. I value these experiences, because, I believe they are the fundamental reasons why, these 
days, I still grow a vegetable garden, recycle as much as I can, and support environmental issues. Presently, I live in the countryside, and I appreciate natural foods and rural surroundings. In my home, I closely monitor our family water consumption, because I view water as a precious commodity. In essence, my mother's influence is a small voice in my mind that constantly reminds me: waste not, want not.

Because I was raised in a household where education was viewed as far more than just schooling, my philosophy of education has been influenced. I value many forms of knowledge; however my fundamental belief about education is that it needs to envelop holistic attributes. More specifically, I believe:

Education is not about a pass or fail, and it cannot be rationally represented through some number. Education is not a process that can be measured through a particular test or instrument. Education is not solely portrayed through academic intelligence. Education is not something that can be filtered through an outsider's judgment. In most simple and accurate terms, education is the journey of life. During the process of education, we, as teachers, sometimes lose sight of that statement. As teachers, it is our responsibility to acknowledge the spirit of the student and draw out his/her inner potential. To bless someone with a thirst for knowledge is as important as being able to spell your first name. (Preston, 2010, p. 4)

I end this article by directing the reader to a point I made at the beginning of the document. My initial hope was that the information threaded herein might resonate with the reader. I now ask the reader: What person inspires you? What holistic educational or dominant life lessons does this person carry? How does this person's holistic education make the world a better place to live? How does this person affect the way in which you view education? I implore you to reflect about these questions, pondering upon how the wisdom and influence of this person, in some small or large way, is embodied in you and, in turn, positively affect the people around you. 


\section{Example of My Mother's Handwritten Responses}

are again \& remen his on Sunday after

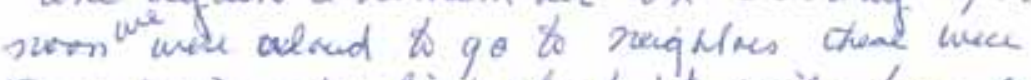
Pugenhaits thly lied abut, $\frac{1}{2}$ mile feom an piace they had g geambuphan / whick is a

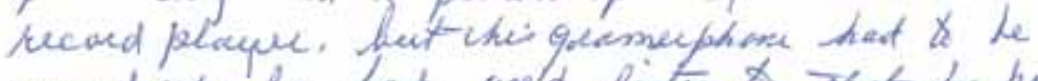

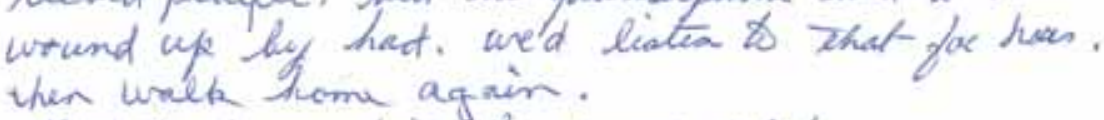

Dad tork wa kids of chuces aldh.

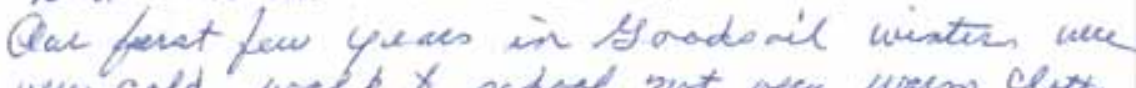
wey cold, waek $x$ achore not wey creem clabs.

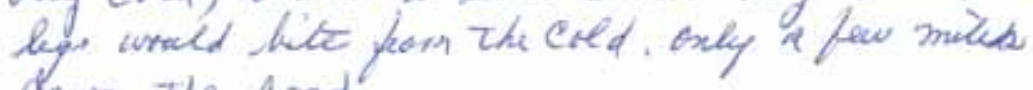
doun the rood?

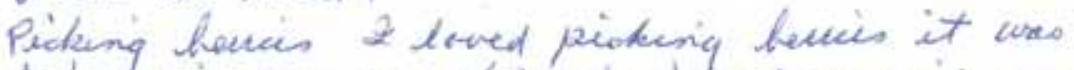
heing with are onen (five of wo) and we girs wa to aing alat b quether

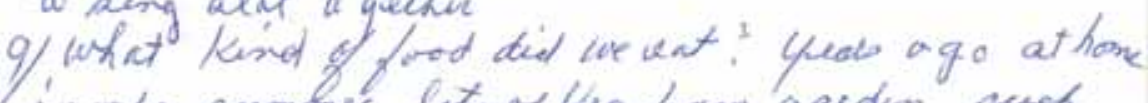
in the sumber lot of leg ham gardin secek

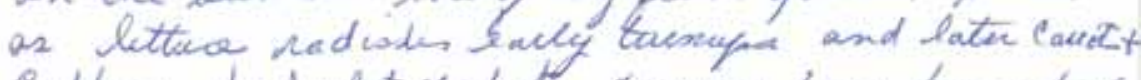

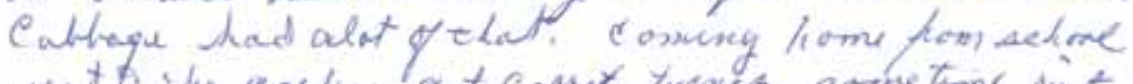

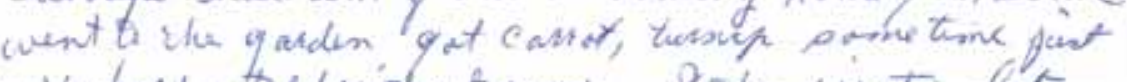

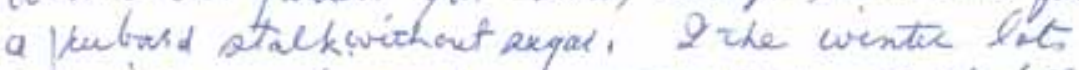
of wield nuet puchas movaer Dest if cha feel

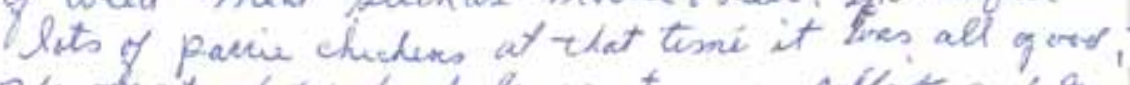

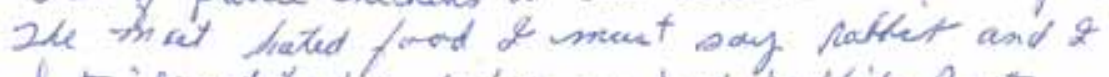
liate it yet to day when we hed halkit 9 at Iny diy, pataties, $9 x$ the wenter we ala

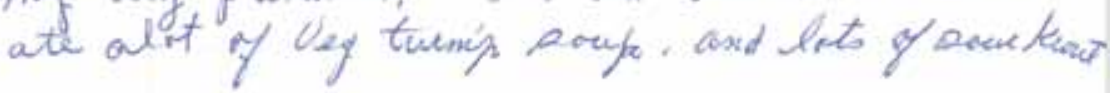




\section{Notes}

1. Even though the American Psychological Association (2010) indicates that the past tense should be used "when discussing another researcher's work" (p. 78), within this article, I break that rule for two reasons. I use the present tense for the sake of consistency (i.e., my mother's history is told in the present tense) and to reinforce an important thread of the article, which is that past knowledge is relevant today.

2. See Appendix A for an example of my mother's written responses. (Note that, on the original paper, other than a small top margin, she made use of the entire page. Also, every sheet of paper she returned had writing on both sides.)

\section{References}

American Psychology Association. (2010). Publication manual of the American Psychological Association (6th ed.). Washington, DC: Author

Bourdieu, P. (1988). Vive la crise! For heterodoxy in social science. Theory and Society, 17(5), 773-787.

Clandinin, D. J., \& Connelly, F. M. (2000). Narrative inquiry: Experience in story and qualitative research. San Francisco: Jossey-Bass.

Clandinin, D. J., \& Rosiek, J. (2007). Mapping a landscape of narrative inquiry: Borderland spaces and tensions. In D. J. Clandinin (Ed.), Handbook of narrative inquiry: Mapping methodology (pp. 35-75), Thousand Oaks, CA: Sage.

Dewey, J. (1916). Democracy and education. New York: Macmillan.

Dewey, J. (1920). Reconstruction in philosophy. New York: H. Holt.

Dewey, J. (1938). Experience and education. New York: Macmillan.

Dewey, J., \& Dewey, E. (1915). Schools of tomorrow. New York: E. P. Dutton.

Elliott, J. (2005). Using narrative in social research: Qualitative and quantitative approaches. London, UK: Sage.
Hansen, D. E. (2006). Preface. In D. T. Hansen (Ed.). John Dewey and our educational prospect: A critical engagement with Dewey's "Democracy and Education" (pp. viiix). Albany, NY: State University of New York Press.

Inman, A. G., Howard, E. E., \& Hill, C. E. (2012). Considerations related to culture in consensual qualitative research. In C. E. Hill (Ed.), Consensual qualitative research: $A$ practical resource for investigating social science phenomena (pp. 187-199). Washington, DC: American Psychological Association.

Kessler, R. (2004). Nourishing adolescents' spirituality. In J. P. Miller, S. Karsten, D. Denton, D. Orr, \& I. Colalillo Kates (Eds.), Holistic learning and spirituality in education: Breaking new ground (pp. 101-107). Albany, NY: State University of New York Press.

Kliebard, H. M. (2006). Dewey's reconstruction of the curriculum: From occupation to disciplined knowledge. In D. T. Hansen (Ed.), John Dewey and our educational prospect: A critical engagement with Dewey's democracy and education (pp. 113-127). Albany, NY: State University of New York Press. 
Lincoln, Y. S., \& Guba, E. G. (1985). Naturalistic inquiry. Thousand Oaks, CA: Sage.

McDonald, H. P. (2004). John Dewey and environmental philosophy. Albany, NY: State University of New York Press.

Miller, J. P. (1997). What are schools for? Holistic education in American culture. Brandon, VT: Holistic Education.

Miller, J. P. (2000). Education and the soul: Towards a spiritual curriculum. Albany, NY: SUNY Press.

Miller, J. P. (2005). Introduction: Holistic learning. In J. P. Miller, S. Karsten, D. Denton, D. Orr, \& I. Colaliollo Kates (Eds.), Holistic learning and spirituality in education: Breaking new ground (pp. 1-6). Albany, NY: State University of New York Press.

Miller, J. P. (2006). Educating for wisdom and compassion: Creating conditions for timeless learning. Thousand Oaks, CA: Corwin Press.

Miller, J. P. (2010). Whole child education. Toronto, ON: University of Toronto Press.

Montessori, M. (1992). Education for human development: Understanding Montessori. Oxford, UK: Clio.

Moore, T. (2004). Educating for the soul. In J. P. Miller, S. Karsten, D. Denton, D. Orr, \& I. Colalillo Kates (Eds.), Holistic learning and spirituality in education: Breaking new ground (pp. 9-15). Albany, NY: State University of New York Press.
Orr, D. (2005). Minding the soul in education: Conceptualizing and teaching the whole person. In J. P. Miller, S. Karsten, D. Denton, D. Orr, \& I. Colaliollo Kates (Eds.), Holistic learning and spirituality in education: Breaking new ground (pp. 87-99). Albany, NY: State University of New York Press.

Palmer, P. J. (1998). The courage to teach: Exploring the inner landscape of a teacher's life. San Francisco: Jossey-Bass.

Preston, J. P. (2010). Educate the educator. Bridges: Reflecting the Scholarship of Teaching and Learning at the University of Saskatchewan, 8(3), 3-4.

Preston, J. P. (2012). Fostering the learning spirituality of students: A teaching narrative. Brock Education: A Journal of Educational Research and Practice, 21(2), 64-79.

Simpson, D. J., Jackson, M. J. B., \& Aycock, J. C. (2005). John Dewey and the art of teaching: Toward reflective and imaginative practice. Thousand Oaks, CA: Sage.

Smuts, J. C. (1926/1987). Holism and evolution. Cape Town, South Africa: N \& S Press.

Stake, R. E. (2010). Qualitative research: Studying how things work. New York: The Guildford Press.

Thomson, K. (2006). Service learning in grades K-8: Experiential learning that builds character and motivation. Thousand Oaks, CA: Corwin Press.

Tolle, E. (2005). A new earth: Awakening to your life's purpose. New York: Dutton.

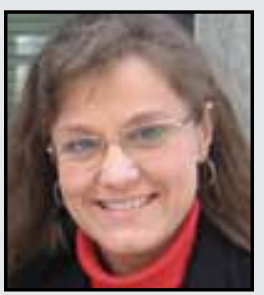

Jane Preston is an Assistant Professor in the Faculty of Education, University of Prince Edward Island. Jane's educational outlook is based on experiences gained while teaching kindergarten to high school classes in Canada, Taiwan, Egypt, and Kuwait. Her research interests include community/parent involvement in school, Aboriginal issues, rural education, and qualitative and narrative research. 